\title{
Tšuktšide ja mõnede teiste rahvaste surnute ja matustega seotud kommetest ja uskumustest
}

Ülo Siimets

Alustaksin seda peatükki katkendiga Lennart Meri raamatust Virmaliste väravas. Tšukotkal olles tahab ta külastada Ueleni kalmistut. Tee peal tuleb talle nõtkel sammul vastu prille kandev tšuktš, kes hõikab:

"Kuhu te lähete?"

"Kalmistule," vastan imestunult, sest mujale see mäkke siuglev tee ei viigi.

"Sinna ei tohi minna," ütleb ta ja astub aeglaselt mu ette, "teil pole sealt midagi otsida."

"Ma ei otsigi," ütlen hämmeldunult, "ma vaatan."

"Ükskõik. See on keelatud."

"Kes mind keelab?"

"Pole tähtis," ütleb ta ja jääb harkisjalu tee peale seisma. "Minge tagasi."

Kanilu vaikib.

Kraamin kaarditaskust välja paberi, mis mind ennegi on täbaratest olukordadest välja aidanud.

"Näete," arvan lootusrikkalt, "mul on luba."

Ta võtab paberi ilmse vastumeelsusega kätte ja laseb silmad üle libiseda.

"See ei loe. Minge siit ära."

Niiviisi on mulle öeldud ainult üks kord ja see oli eesti kolhoosis Musta mere ääres, kus ütlejaks oli kolhoosi purujommis aseesimees. Siin aga seisab mu ees kaine ning rahulik inimene, kes pilku langetamata mulle otsa vaatab. Mu uudishimu kasvab. Istun mättale maha. Mees ütleb Kanilule midagi teravas toonis. Kanilu puudutab mind ôlast.

"Lähme siit ära."

"Ei mõtlegi."

Nad vahetavad mõne lause ja tundmatu lahkub. Kanilu ütleb:

http://haldjas.folklore.ee/tagused/nr25/siimets.pdf 
"Me peame siit kohe ära minema."

"Pagan võtaks, mis siis lahti on?"

"Ta ei luba sind kalmistule."

"Mis lubaja tema on?"

"Ta ütles, et läheb püssi järele."

Ma ei usu oma kôrvu. Puhken naerma. Kanilu ei naera. Kehitan õlgu ja hakkan edasi astuma. Kanilu jääb seisma.

"Mina ei tule."

Mul ei õnnestu teda ümber veenda. Vahel juhtume korraga üle õla vaatama. Viipan teda kaasa. Poiss raputab pead ja kaob majade vahele.

[---]

Lõpetan oma pika mägironimise laguuni ääres tundraastangul. Loojuva päikese taustal on lauged künkad tumedad ja selgepiirilised, kuid siin üleval kirendab tundra ikka veel oma leigete värvide poolunes. Kahvatupunane kulu, kahvatupruun sammal, hallid kivid, pleekinud luud, mehe kolp. Kägaras naine, kingad jalas ja teekonnariistad kõrval. Laps. Mõned pehkinud ristid ja ajast puretud kalmekastid. Igikeltsa ja kalmete maal ei kaevata haudu. Lemming ajab end tagakäppadele, jääb uudistama ja liigub ninasõõrmeid väristades lähemale, ronides üle reieluu. Kõik on lihtne ja lõplik. Luud külitavad nii igapäevases asendis, et näed inimest usalduslikult rohule puhkama heitmas ja meeled tõrguvad kasutamast sõna s u $r$ n u. Need on muistsed inimesed, "mehed muistsed maaalused”, nagu meil öeldi, kes siin päikese ja vihma käes, minu ja minu saapakontsa usutleva lemmingi silmade all jätkavad oma väsimatut reisi läbi looduse, elavad rohuna, kõnnivad loomana, valvavad iseenda rännuteed karmi tšuktšina, kelle ägedat keeldu ma nü̈̈d hakkan mõistma, mõistma ja hindama. Igatahes ei tunne ma end selles paigas ebasoovituna. Ei puudu siin ka lihavate tiibadega must kaaren, kuid temalgi on oma töö, ta ei kanna kaduviku, vaid elu mõtet, niihästi siin kui terves arktilises Beringis. Need alasti kondid ongi Ueleni Trooja, sada põlvkonda käest kätte antud elu (Meri 1974: 309-310, 314).

Seda, miks Lennart Merit ei lubatud tšuktši surnuaiale, saate lugeda järgnevast loost. 
Jõudsime mingi Anadõri lisajõe äärde. Jõgi oli üsna lai ja juba paari meetri kaugusel kaldast oli vesi nii sügav, et ulatus üle pikkade säärtega kalamehekummikute. Vool oli tugev ja põdrakari suunati jõge mööda ülespoole. Ejgeli ütles: ülesvoolu minnakse seni, kuni jõutakse koolmekohani, et saaks karjaga rahulikult üle jõe minna. Küsimus ei olnud muidugi põhjapõtrades, sest need ujuvad suurepäraselt. Hoopis karjustel oli raske läbi jääkülma vee teisele kaldale pääseda. Ei oska ju enamik tundratšuktše ujuda ja kummipaate kui liigset kandamit ei olnud meil kaasas.

Pärast mõnepäevast liikumist hargnes jõgi kaheks väiksemaks haruks. Jõest mõnekümne meetri kaugusel paistsid ühe mahajäetud jaranga jäänused.

"Näe, ongi vare," ütles Ejgeli.

Jaranga jäi teisele poole jõge. Vool oli ikka veel kiire ja ma ei saanud lähemale minna. Arvasin, et sõna vare viitab lagunenud jarangale ja noogutasin arusaaja moega. Tšuktši keeles on väga palju soome-ugri keeltega samakõlalisi ja samatähenduslikke mõisteid. Aeg-ajalt kuulsin karjuste jutus tuttavaid sõnu, mis tähendasid sama asju või tegevust nagu eesti keeles. Jukagiiri keele sõnaraamatu koostanud Johannes Angere andmetel leidis Karl Bouda jukagiiri keelest üle saja uurali-ugri sünonüümi ja kaks korda rohkem tšuktši keelest. K. Bouda pidas seetõttu tšuktši, kamtšadaali ja korjaki keelt soome-ugri sugulaskeeleks. Paljudel teadlastel on aga vastupidine arvamus.

Hiljem selgus, et vare pole mitte majavare, nagu eesti keeles, vaid see sõna tähendab tšuktši keeles jõe hargnemiskohta, millele Ejgeli käega viipaski. Kas nii või teisiti, aga siit sai alguse jutt vanadest jarangadest ja sellest, miks need jäetakse tundrasse vedelema.

Ejgeli jutustas, et kui suguvõsa viimane üksi jarangas elav tšuktš sureb, jäetakse jaranga tühjalt seisma, kuni eluase ise ära kõduneb. Sellisest jarangast ei tohi võtta ühtegi asja. Keelatud on isegi jarangade ehitamiseks nii vajalike lattide kaasavõtmine, kuigi uute korralike lattide leidmine on metsatundras raske. Kui keegi võtab sealt mingi asjakese, kas või lati, võivad sellele järgneda suured õnnetused. Sellega sa võid kaasa tuua surnud suguvõsa hinged, ning tagajärjeks on see, et see hing või need hinged asuvad elama sinu jarangasse. Kuna nad on ketlja käsilased, on neil lihtne kahjustada sind ja sinu perekonda. 
Sellest ei hooli muidugi tan jidest geoloogid, kes armastavad jaranga kuivadest puudest lõket teha. Nad ei tea, millise needuse nad endale kaasa saavad, ja seepärast on nendega tundras alatasa raskeid, isegi surmaga lõppevaid õnnetusi.

Isegi kui keegi kaotab kolimisel jaranga ridva, ei või sa seda võtta ja panna oma jaranga lattide hulka, sest see võib olla meelega maha jäetud. Ka sel juhul võid sa tuua halva enda jarangasse. Küll on lubatud tee pealt leitud latte kasutada lõkkematerjalina, siis põleb nendes olev halb ära. Samas aga ei tohi siiski võtta lõkkematerjali mahajäetud jaranga lattide hulgast, sest seal võivad elutseda väga tugevad vaimud, kes võivad su peale vihastada ja sind taga kiusama hakata.

Muide, samasugune komme on meil Eestis kohati Setumaal. Olin 1984. aasta suvel Petseri rajoonis Pankjavitsa lähedal külas ühel oma tuttaval. Tema maja õuelt oli näha mäe otsas asuvat vana kiviveskit ja seal lähedal taluvaremeid. Talu oli kuulunud Rosenbergi suguvõsale. Varemete vahel kolades leidsin väga palju saksakeelseid raamatuid. Nende hulgas oli nii väärtuslikke teatmeteoseid, armastusromaane, lasteraamatuid, sopakaid kui ka igasuguseid muid raamatuid. Paljud raamatud olid niiskusest riknenud, aga nende hulgas oli veel üsna asjalikke. Valisin sealt välja mulle meeldivad ja tahtsin kaasa võtta, kuid mulle öeldi, et vana peremees oli avaldanud enne oma surma soovi, et kõik asjad jääksid talus nendele kohtadele, kus nad on. Seega ei tohtinud keegi sealt midagi võtta, sest muidu hakkavat vana Rosenberg kodus kummitamas käima. Ma ütlesin küll, et viin ju raamatud oma koju, aga vastuseks ütles sealne taluperemees, et tema elab nende varemete ligidal ja kardab, et kodukäijad tulevad hoopis teda külastama. Jätsin raamatud varemetesse, sest kodukäijaid ma sõbra majja küll meelitada ei tahtnud.

Liikusime põdrakarjaga mööda jõge ülespoole, või nagu tšuktšid ütlevad, gõrgoli suunas. Huvitav on tõdeda, et sellelgi sõnal on nende keeles sama tähendus mis eesti keeles - gõrgol tähendab kõrgemal, ülalpool olevat, ülemist.

Ilmad olid juba jahedamad ja putukaid lendles õhus vähem. Seetõttu oli põdrakari rahulik ja jäi, olles jõest vett joonud, puhkama. Istusime kividele, tegime tule üles ja keetsime teed. Ülevalt paistis hästi kätte mahajäänud jaranga all orus. Mõtlesin selle jaranga vii- 
masele omanikule ja mulle meenus belamuudi Miša Bogratšovi jutt tšuktšide ja teiste kohalike matusekommetest.

Me olime tol korral veel puumajadest külas - Vaegis.

Nõukogude armee aastapäev oli üleliiduline püha ja kohalikus kaupluses anti igale soovijale võimalus osta kaks pudelit peeti (nii oli piirituseveini rahvapärane nimetus). Paljudel meestel oli tekkinud kodus naistega joomise pärast probleeme. Seetõttu kogunesid Vaegi nooremad mehed meie korterisse, et soojas poissmehekorteris see vein ära juua. Pealegi oli üheskoos ka lõbusam, sest mängiti kaarte ja lobiseti niisama.

Seekord läks jutt kuidagi matusekommetele. Miša jutustas, et kui ta oli noor, suri tema kodukülas keegi kohalik. Enne matust küsis šamaan surnult, kuhu ta tahab maetud saada. Muidugi andis surnu talle vastuse, kuhu ta keha viia tuleb. Surnu pandi nartale. Narta oli kaetud põdranahkadega, millele asetati surnukeha. Ka laip oli põdranahkadega kaetud. Kõikide nahkade karv oli pööratud surnu poole.

Narta ette rakendati põder. Šamaan võttis oma bubini ja hakkas seda põristades surnu poolt nimetatud koha suunas minema. Ta põristas bubinit, ise hüpeldes ning tantsiskledes. Tee ei läinud mitte otse, vaid tehti mitmeid sõlmi ja ringe, sest nii on surnu hingel raskem leida tagasiteed.

Jõuti surnu nimetatud kohta. Sinna laoti tuleriit. Et lähedal puid ei olnud, olid kuivad puud külast kaasa toodud ja neid toodi veel juurde kusagilt lähemal asuvast põõsastikust. Šamaan hüples bubinit põristades ümber puuriida ja selle peale asetatud narta ning ümises oma loitse. Siis tuli ta hüpeldes, keerutades ja bubinit mängides surnu juurde.

Šamaan puges surnu peale asetatud põdranahkade alla. Ta lõikas terava noaga lahti surnu kõhu ja eemaldas sealt sisikonna. Seejärel lõikas ta läbi surnu kõikide liigeste kõõlused. Selle toimingu eesmärk oli, et surnu ei saaks pärast lõkke süütamist liigutada. Siis tuli šamaan põdranahkade alt välja.

Seejärel tapeti puuriida juures koerakutsikas. Tema verega piserdati puuriita ja sellel nahkade all lebavat surnut. Kutsikas pandi ka puuriidale ja seejärel pandi puuriit põlema. Lõkke ääres ohverdati surnule põder, kelle peielised sealsamas ära sõid. Ülejääk visati lõkkesse.

Selle peale rääkis Vasja Startsev, et algul, kui ta sõjaväkke võeti, oli ta väljaõppel Vladivastoki lähedal. Nendele oli ühel pühapäe- 
val antud linnaluba. Vladivostokki oli tükk maad, bussid ei käinud ja nad läksid väeosa lähedal asuvasse külla tüdrukuid vaatama.

Sel päeval oli külas aga ühe kohaliku matus. Tema arvates oli see kohalik tüdruk mandžu, nanai või mingist muust kohalikust rahvusest. Küla lähedal viis purre üle jõe. Sealses võsas olevale lagendikule oli laotud puuriit. Surnu oli tuleriidale pandud. Tal ei olnud kõõluseid läbi lõigatud ega sisikonda välja lastud. Puuriit süüdati põlema. Korraga oli surnu ennast tuleriidal liigutama hakanud. Algul olid liikunud käed ja jalad, siis oli surnu ennast istuli ajanud ja tuleriida otsas siia-sinna väänelnud. Riided ja juuksed olid leegitsenud ja muutnud muidu valge lõkkesuitsu mustaks. Kõige koledam oli surnu nägu. See tõmbus kuumusest grimassi paljastades valged hambad.Vaatepilt oli nii kole, et Vasjal viirastus hiljem see kohutav pilt unenägudes.

Otto von Kotzebue kirjutas oma ümbermaailmareisil Kamtšatkal päevikusse järgmist:

Täiskasvanud lapsed osutasid vähe armastust oma vanemate vastu ning jätsid nad kõrges vanuses täiesti hooletusse, lü̈̈es nad küll ka surnuks, kui nad iseendale ja lastele koormaks muutusid. Neile ei tulnud mõttessegi, et nad sellega oma lastekohustusi rikuvad. Niisamuti mõrvasid nad oma põduraid ja nõrku lapsi, et neid hädadest ja viletsast elust säästa.

Kui keegi kodustest suri, ei maetud ta laipa mitte maha, vaid veeti kaela ümber seotud rihma otsas välja, lastes koertel laibast kõht täis sü̈̈a. Keda need loomad ära ei põlanud, sellest arvati, et ta hakkab teises ilmas sõitma kõige peenemate koertega (Kotzebue 1978: 165).

Rääkisin need lood Ejgelile (kamtšatkalaste loo lugesin mõned aastad hiljem Eestis olles) ja küsisin, kas eelnimetatud jutud on tema arvates õiged. Ejgeli vastas, et mandžudest ei tea ta midagi, aga see tšuktši matus on küll üks siinsete matuste lihtsustatud variantidest. Nii võib see olla belamuudide juures, aga mitte tõeliste tšuktšide-cawcude-juures.

Ejgeli ei olnud Miša Bogratšov ise tõelist, vanade kommetega matust näinud. Igatahes karjakasvatajatest tšuktšide juures valitseb uskumus surnu (tšuktši keeles peneeljön) kohesest tagasipöördumisest jarangasse, kui keegi matuste ajal trummi põristab, karjub või isegi müra teeb. Osal (või isegi enamikul) tšuktši hõimudel 
on keelatud trummi põristamine kolme päeva jooksul alates inimese surmast.

Surnute puhul on tähtis täpne kommete täitmine. Iga vale liigutus või mõne kombe täitmata jätmine toob kaasa selle, et surnust saab sinu vaenlane. Õigetest kommetest kinnipidamisel saab surnust sinu perekonna abiline.

Kuni surnu lebab jarangas, ei ole ta ohtlik. Ka hiljem on enamik surnutest head hinged. Ohtlikud on kurjad, tagasipöördunud surnud. Nendel on suur tahtmine teha inimestele halba. Nad toovad endaga elavatele palju muret ja kurvastust kaasa.

Nende hulgas on üks eriti ohtlik surnute kategooria - "lõplikult" surnud - , kes ei saa enam mitte kunagi siia ilma uuesti sündida. Nad on elanud juba maa peal valesti või on neil mingi matmistseremoonial tehtud vea tõttu suletud pääs surnute riiki. Siis kolavad nad kahe ilma vahel ja on seetõttu väga kurjad. Sellistest surnutest saavad ketljade abilised.

Surnute asjade kasutamine ei too kaasa midagi halba. Halba võib aga teha surnu ise, kui ta ei ole rahu saanud.

Väga ohtlikud on vägivaldselt tapetute surnukehad. Nad on tapetud näiteks tundras ja jäetudki sinna vedelema. Sellise surnu juures on tema hing, kes hakkab tülitajat jälitama. Kui sa lähed otse koju, ei ole sul loota mingit pääsu kurjade jõudude eest.

Sellise surnu leidmise korral tuli rakendada kavalust. Näiteks lähed kõigepealt naaberkülla, siis oma kõrvaljarangasse. Kui lõpuks oma jarangasse jõuad, nühid end koerakutsikaga üle. Kutsikal on imepärane omadus võtta kõik halb ja haigused endasse. Niiviisi eksib kuri teelt. Ta võib pidama jääda kusagil naabrite juures. Kui ta sulle ikkagi järgneb, võtab koerakutsikas kindlasti kurja sinu küljest ära. Sel juhul jääb kutsuke haigeks või isegi sureb, aga sina ilmselt pääsed. Muidugi on juhuseid, kus kuri on tugevam, aga seda tuleb ette harva.

Kui on märgata, et surnu on jarangasse tagasi tulnud, kutsutakse šamaan, kes viib trummi põristades läbi surnu jarangast väljahirmutamise riituse. Muidu küll trummi ei mängita.

Kui tšuktš sureb, võetakse ta riidest lahti ja pannakse magamisasemel asuvale põhjapõdranahale, mille karv on pööratud ülespoole. Magamisase asub pologis (õhukesest riidest telk jaranga sees). Talle pannakse peale teine põhjapõdranahk, karv kadunukese poole. Nahad pannakse surnu ümber selleks, et päike ei näeks surnu alasti keha. Kadunukese keha näitamine päikesele või päevavalgu- 
sele pidi olema väga häbiväärne tegu. Eriti solvav pidi olema surnu suguorganite paljastamine päikese käes.

Surnu juurde jäetakse valvesse vähemalt kaks inimest. Siis ei saa surnu tõusta ja kahjustada teisi jarangas olijaid. Üht inimest võib surnu terroriseerima hakata.

Teisel päeval pärast surma sooritab "kaitsja" mitmed toimingud, et vähendada surnu kurja mõju kaaskondsetele. Jagatakse välja uued amuletid. Need on punutud põdravasika kuivatatud jalakõõlustest kaitseks kurja vastu ja seotakse ümber parema käe randme. Selle jaranga taga, kus asub surnu, tapetakse kutsikas. Kutsika laip jäetakse jaranga taha lebama kogu matuste ajaks. See on kaitseks kurja ja ketljade vastu.

Surirõivad õmmeldakse valgest parknahast. Tavalise, punase parknaha kasutamine on keelatud. Surirõivasteks kasutatavate nahkade juures on eelistatavad valgekarvalised põdranahad. Surnut ei tohi matta tema igapäevases riietuses, sest see solvab surnut ja võib olla ka üheks põhjuseks, miks surnu ei ole rahul ja muutub kurjaks ketlja abiliseks.

Torbased (põhjarahvastel kasutatavad kõrge säärega jalanõud, millel all ja üleval sidumisnöörid) õmmeldakse hülge- või merihobunahast. Need on küll kallid ja seda nahka on raskem saada, aga ega surnu tohi tavalistes põdrakamusest (põhjapõdra jalanahast) torbastes ega laparkades (nöörideta torbased) ringi käia. Õmblemisel ei tohi loomasoontest niidile teha õmbluse otsa ega niidi lõppemisel sõlmi, sest iga sellise sõlmega viiakse hädaohtu üks laagris olevatest kaaslastest.

Surnule pannakse kaasa tema igapäevased vööl olevad esemed ja tema igapäevased rõivad. Eriti ohtlik on siinjuures surnu jarangade juurest äraviimise päeval trummi põristamine, mis toob kindlasti kaasa surnu tagasipöördumise jarangasse.

Äraviimise päeva hommikul tehakse lõke jaranga sissekäigu juurde. Tapetakse mõned põhjapõdrad ja viiakse läbi lõkkele ohverdamise riitus. Seejärel surnu riietatakse. Surnu söök pannakse laipa katva pealmise põdranaha alla. Põhjapõdranaha sisse surnu suu kohale lõigatakse auk, mille kaudu lükatakse surnule koheseks söömiseks natukene liha ja "tšuktši võid" (keedetud põdrakondirasv).

Hüvastijättu alustavad kõige lähemad sugulased, neile järgnevad "saatjad" ja siis teised külalised. Hüvastijätul võetakse surnu käsi ja pannakse ümber oma piha. Seejärel võetakse oma käega 
surnu ümbert kinni ja soovitakse talle head teekonda surnute riiki.

Toimub sümboolne surnu pesemine. Võetakse väike kauss ja peotäis kuivatatud turbasammalt ning samblatükki kaussi kastes imiteeritakse surnukeha pesemist. Riituseesemed antakse üle järgmisele "saatjale", kes kordab sama toimingut. See kestab, kuni kõik saatjad on sümboolse pesemise läbi viinud.

Surnu riietamise toiming viiakse läbi käsikaudu, sest keegi ei tohi näha surnu nägu ega tema paljast keha, muidu läheb riietajatel halvasti. Sellepärast rõivastab kaks või kolm lähedaste paari kahel pool surnut istudes teda ühiselt.

Pärast riietamist tõmmatakse surnule kapuuts pähe. Suviste matuste puhul, mil tšuktšid kannavad ilma kapuutsita nahksärki, õmmeldakse see spetsiaalselt särgi külge. Surnu näole pannakse nahast rätik. Riietamise ajal rahustavad kõik saatjad surnut, andes talle mõista, et tal on aeg asuda pikale teekonnale.

Meessurnu igapäevane vöö ja naissurnu karvase krae tükid jagatakse omavahel. Tšuktši naised õmblevad neile ümber spetsiaalse pärlite ja helmestega kaunistatud koti. Seda amuletti kutsutakse jenaliks. Niisugust kotikest kantakse vööl või riputatakse kas jarangasse või pologisse. Selle omanikul on jenali näol alati kaasas tugev kaitsevaim, kes hoiab temast pahandusi eemale.

Pärast riietamist viiakse surnu jaranga keskele, asetatakse peaga väljapääsu suunas ja viiakse läbi tseremoonia, et saada teada, kuhu surnu tahab maetud saada ja kuidas tuleb matused korraldada. Maetakse kahel viisil: surnukeha viiakse tundrasse või toimub põletusmatus. Paljud vanakesed on oma soovi sugulastele juba varem teatavaks teinud. Kui seda ei ole aga tehtud, laseb üks lähimatest sugulastest siduda oma pea külge puukaika (tavaliselt nartajuhtimise kepi). Esitatakse küsimusi. Kui kaigas muutub raskeks ja pea kaldub ettepoole, on vastus eitav, kui pea muutub kergeks ja kaigas kaldub tahapoole, siis jaatav. Selliseid küsimusi korratakse jarangas erinevates kohtades ja mitu korda, et saada kindlasti õige vastus, et surnu hiljem elusate peale pahane poleks.

Mõned tšuktšid kasutavad ennustusküsitlusel kaalumistehnikat. Kui küsimuse peale näiteks rihma otsa riputatud põhjapõdrapealuu või muu asi läheb väljasirutatud käe otsas raskemaks, on vastus eitav, kui kergemaks, siis jaatav.

Surnu viiakse jarangast välja läbi tagumise seina. Põdranahkadega kaetud surnukeha lükatakse jaranganahkade alt läbi ja pühi- 
takse või kõrvaldatakse hoolikalt surnu väljaviimise jäljed, et surnu ei leiaks tagasiteed jarangasse. Surnu pannakse nartale ja seotakse kinni uute nahknööridega. Ka narta on tavaliselt uus või üks parimaid olemasolevatest.

Narta asetatakse jaranga sissepääsust vasakule kahe teiba peale, tagumise otsaga matusekoha suunas. Seejärel algab ennustamine - kui narta hakkab kergesti liikuma, on kõik korras, kui ei, siis pole surnu millegagi rahul ja tuleb korraldada uus ennustamine, et saada teada, millega kadunu rahul ei ole. Kui kõik on korras, võib jarangade juurest lahkuda.

Saatja istub nartale ja sõidab valitud matusepaigale. Kui surnu on valinud oma teekonnaks "surnute riiki" jalgsimatka, peavad kõik matuselised minema matuseplatsile jala. Surnu viiakse ka sel juhul matuseplatsile matusekorraldaja nartaga.

Maa peale laotakse kividest põhja-lõunasuunaline ovaal. Ringi lõunapoolsesse otsa kive ei panda, see jääb lahti. Tapetakse üks või kaks põtra. Kui tegemist ei ole põletusmatusega, põdrad nülitakse. Surnu võetakse nartalt ja pannakse kiviringi keskele, pea põhja suunas. Surnu jalgade kõrvale kahele poole asetatakse teibad - neid kahte teivast läheb surnul vaja surnute riiki pöördumisel. Kadunu juurde tulevad teravate nugadega saatjad. Nad põlvitavad surnu juurde ja kraaksuvad kolm korda varese kombel, et ketljat segadusse ajada. Varese kraaksumist kuuldes arvab ta, et surnu juures tegutsevad varesed, ega tule lähedale.

Saatjad sõlmivad rihmad lahti ja hakkavad surnu riiete küljest tükke lõikama. Iga lõigatud riidetüki asemele asetavad nad põhjapõdra kere küljest lõigatud lihatüki. Ka surnu alt tõmmatakse riided ära ja lõigatakse samuti tükkideks. Nii toimitakse seni, kuni kogu surnukeha on lihakihiga kaetud. Ohverdatud põhjapõtradel murtakse kõik jalaluud ja lõigatakse koos kolbatükiga ära sarved. Riidetükid asetatakse surnust paremale. Surnu kõrvale asetatakse talle hädavajalikud esemed: tubakakott, piip, nuga, tael, tulekivi jne. Surnu kõrvale asetatakse ka pisikene sümboolne puust aerudega paat, et surnu saaks sellega sõita surnutemaa jõest üle või mööda jõge vajalikku kohta.

Kaitsja lõikab terava noaga lahti surnu rinna ja kõhu ning võtab välja sisikonna ja südame. Süda ja maks lõigatakse pooleks ning vaadatakse, kas sinna on pugenud ketljad või muud pahad vaimud. Seejärel lõikab kaitsja läbi surnu kõri ja lahkub surnu juurest. Vii- 
mane toiming on vajalik selleks, et surnu ei saaks peielistele järgneda ega kehasse tagasi pöörduda.

Ka põletusmatus toimub samamoodi. Vahe on ainult selles, et surnut ei võeta narta pealt maha, vaid narta asetatakse puuriidale ja surnu peale kuhjatakse paks kiht puid. Sel juhul ei saa surnu ennast eelkirjeldatud mandžu tütarlapse kombel püsti ajada.

Matusepaigalt lahkudes jätab kaitsja tagasiteel maha surnupesemiskausikese ja samblanuustiku. Lahkujad loevad erilisi lahkumisloitse. Lahkumisteele, kas lume või maa peale, tõmmatakse pikk tugev joon, mis ei lase surnut elavatele järgneda. Sama ülesannet täidavad ka tee peale maha jäetud surnupesemiskausike ja samblanuustik.

Enne jarangasse sisenemist loetakse jälle kindlat loitsu.

Tapetud põdra (või põtrade) nahad pannakse sellesse pologisse, kus lebas surnu. Sinna jäävad need viieks päevaks. Vanad naised jagavad peielistele veel kord kuivatatud vasikasoontest põimitud paelu randme ümber sidumiseks.

Järgmisel päeval minnakse uuesti matusepaigale. Kui matusest võtab tavaliselt osa väga vähe lähedasi, siis järgmisel päeval läheb matmispaigale peaaegu kogu küla. Kui öö jooksul on surnut külastanud loomad ja osa liha on ära söödud, on kõik korda läinud. Kui ei, siis ei ole surnu millegagi rahul. Talle tuuakse kingituseks põdra jalaüdi, peaaju, maksa, suhkrut, teed, tubakat. Keegi ei tohi tulla kingituseta.

Surnu sugulased tapavad põdra ja see jagatakse külaliste vahel. Teine põder süüakse kohapeal. Tapetud põhjapõtrade jalaluud purustatakse ja jalaüdi võetakse välja. Sarved raiutakse koos pealuu tükiga kolju küljest lahti ja asetatakse põhja-lõunasuunaliselt surnu pea kõrvale. Põdrasoolikad visatakse kadunu kõrvale maha. Põhjapõdra magu lõigatakse lõhki ja selle sisu puistatakse ümber surnu laiali. Põdra pea keedetakse suures katlas ja lihaleemest tehakse veresuppi.

Kaitsja juhtimisel korratakse loitse. Seejärel ennustatakse kaalumise teel, et saada teada, kas surnu on rahul.

Jarangade juures tapetakse veel üks põhjapõder ja loitsitakse. Jarangas pannakse aukohale surnu riiete küljest lõigatud nahatükike, mis on kaasa võetud viimaselt ohverdamistalituselt. Selle ette laotatakse ja sellele pakutakse toidupalasid. Viie päeva pärast saab sellest nahatükist perekonna amulett - kaitsevaim. Igaks juhuks kolitakse samal päeval ka jaranga teise kohta, et surnu hing seda 
üles ei leiaks. Matuseplatsi hakatakse külastama igal aastal ja tuuakse surnule ohvreid.

Vahepeal oli põdrakari muutunud rahutuks. Ejgeli kutsus ära koera, kes loomi ringist välja ei lasknud, ja me jätkasime teed gõrgoli suunas.

Tšuktšimaal oldud aja jooksul mul matustel osaleda ei õnnestunud. Kui jõudsin tagasi puumajadest külla, küsisin õpetaja Niina arvamust Ejgeli jutu kohta. Tüdruk ütles, et sellised matusekombed on säilinud kohati jarangade juures. Kui inimene sureb puumajadest külas, maetakse ta vene kombe järgi. Kaugemal põhjas viiakse surnu kirstu ja kaasapandud esemetega küla taha surnuaeda. Mõned tšuktšid korraldavad rahvuskülades ohverdamistalitusi, aga venestunud külades seda enam ei tehta.

Nüüd tagasi Lennart Meri Ueleni-käigu juurde. Nagu Eigeli jutust järeldub, eksis ta kohalike tavade ja uskumuse vastu. Esiteks, keegi ei tohi näha surnu nägu. Ent L. Meri kirjeldab, kuidas surnuaial vedeleb maas Kägaras naine. Laps. Pleekinud luud, mehe kolp. Teiseks teame, et kui leiad tundrast surnu säilmed, ei tohi sa otse koju minna, vaid pead seda tegema naaberküla kaudu, sest muidu võib paha vaim ketlja ehk kele sulle järgneda. L. Meri läks aga surnuaialt otse hotelli. Kolmandaks, sa pead tõmbama enda kaitseks lume või maa peale joone, mis ei lase surnul elavatele järgneda. Sama ülesannet täidavad ka tee peale maha jäetud surnupesemiskausike ja samblanuustik. Kohalike kombeid mittetundval inimesel jääb see tegemata. Neljandaks, koju jõudes tuli halb üle kanda kutsikale, et ta vaimud sinu küljest eemaldaks. Jaranga suu ette tuli teha lõke ja jaranga taga ohverdada kutsikas. Kust pidi aga Lennart Meri saama selleks otstarbeks kutsika!

\section{Kirjandus}

Kotzebue, Otto von 1978. Reis ümber maailma aastail 1823-1826. Tõlk Ülo Kurvits. Maailma ja mõnda. Tallinn: Eesti Raamat.

Meri, Lennart 1974. Virmaliste väravas. Tallinn: Eesti Raamat. 